\title{
Doxycycline increases neurogenesis and reduces microglia in the adult hippocampus
}

\author{
Sebastien Sultan ${ }^{\dagger}$, Elias Gebara ${ }^{\dagger}$ and Nicolas Toni * \\ Department of Fundamental Neurosciences, University of Lausanne, Lausanne, Switzerland
}

\section{Edited by:}

João O. Malva, University of

Coimbra, Portugal

Reviewed by:

Jorge Valero, University of Coimbra, Portugal

William Gray, Cardiff University, UK

\section{*Correspondence:}

Nicolas Toni, Department of Fundamental Neurosciences,

University of Lausanne, 9, rue du

Bugnon, 1005 Lausanne,

Switzerland

e-mail:nicolas.toni@unil.ch

${ }^{\dagger}$ These authors have contributed equally to this work.
Adult hippocampal neurogenesis results in the continuous formation of new neurons and is a process of brain plasticity involved in learning and memory. Although induciblereversible transgenic mouse models are increasingly being used to investigate adult neurogenesis, transgene control requires the administration of an activator, doxycycline (Dox), with unknown effects on adult neurogenesis. Here, we tested the effect of Dox administration on adult neurogenesis in vivo. We found that 4 weeks of Dox treatment at doses commonly used for gene expression control, resulted in increased neurogenesis. Furthermore, the dendrites of new neurons displayed increased spine density. Concomitantly, Iba1-expressing microglia was reduced by Dox treatment. These results indicate that Dox treatment may interfere with parameters of relevance for the use of inducible transgenic mice in studies of adult neurogenesis or brain inflammation.

Keywords: dentate gyrus, hippocampus, adult neurogenesis, doxycycline, tetracycline, gene expression regulation

\section{INTRODUCTION}

Adult neurogenesis occurs mainly in two discrete areas: the olfactory bulb and the dentate gyrus (DG) of the hippocampus (Altman, 1969). The process of adult neurogenesis consists in several steps: First, the division of adult neural stem cells, residing in the subgranular zone (SGZ) of the DG (Gage, 2000). Adult neural stem cells display a radial glia like (RGL) morphology, characterized by a unique radial process extending through the granule cell layer and branching into the molecular layer and by the expression of several markers such as the astrocytic glial fibrillary acidic protein (GFAP) and nestin (Huttmann et al., 2003; Ehninger and Kempermann, 2008). RGL cells divide asymmetrically to self-renew and yield highly proliferative transit-amplifying progenitors (TAPs), which do not have a radial morphology and express nestin and the T-box brain gene 2 (Tbr2), but not GFAP. TAPs give rise to immature neurons, which express the immature neuronal marker doublecortin (DCX) and differentiate into mature, NeuN-expressing neurons (Gage, 2000; Ma et al., 2009; Yao et al., 2012). During their maturation, young neurons project their dendrites into the molecular layer, form dendritic spines, which receive synaptic inputs from perforant path afferences from the entorhinal cortex (Gage, 2000; Van Praag et al., 2002; Laplagne et al., 2006; Toni et al., 2007; Toni and Sultan, 2011). They also project their axons to the hippocampal CA3 area and establish synaptic connections with postsynaptic inhibitory interneurons and excitatory pyramidal neurons (Toni et al., 2008). After 8 weeks, new neurons are morphologically and functionally indistinguishable from neighboring neurons and are completely integrated into the hippocampal network (Laplagne et al., 2006; Ge et al., 2008).

The mechanisms regulating adult neurogenesis are highly relevant for our understanding of brain plasticity and for the potential use of these cells as therapeutic targets. Indeed, although their role remains unclear, increasing evidence suggests that new neurons are involved in mechanisms of learning and memory (Van Praag et al., 1999, 2002; Saxe et al., 2006, 2007; Dupret et al., 2007; Trouche et al., 2009; Massa et al., 2011; Gu et al., 2012; Shors et al., 2012; Tronel et al., 2012) as well as in depression and mood control (Santarelli et al., 2003; Samuels and Hen, 2011). However, one of the great difficulties in studying adult neurogenesis in vivo, is that the mechanisms regulating neuronal proliferation, differentiation and survival also play a role during brain development and therefore, their manipulation leads to prenatal death or morbidity. This experimental caveat can be circumvented by the use of inducible transgene expression, such as the tetracycline regulatory system, controlled with the administration of doxycycline (Dox) (Gossen and Bujard, 1992; Zhou et al., 2006; Chow et al., 2012). This elegant system enables the bi-directional and non-invasive regulation of gene expression. Furthermore, by controlling the timing of the genetic manipulation, genes necessary for cell survival can be manipulated without affecting brain development. However, although inducible transgenic mouse models are increasingly being used for studies of adult neurogenesis, the effect of Dox on adult neurogenesis is unknown. Dox is a synthetic antibiotic of the tetracycline inhibitors group, with reported effects on pain, inflammation and neuroprotection (Clark et al., 1997; Cho et al., 2009; Jantzie and Todd, 2010; Yoon et al., 2012). Thus, the use of Dox to control gene expression may potentially bias phenotypic analysis of adult neurogenesis with the introduction of confounding factors.

The aim of the present study was to examine the potential effects of Dox on adult neurogenesis in vivo. We have used a per os administration route, which corresponds to the main experimental protocol for the control of transgene expression. Using immunohistochemistry and viral-mediated labeling, we have analyzed the effect of Dox on RGL cells, TAPs and on the 
differentiation, survival and synaptic maturation of new neurons, as well as on microglia.

\section{MATERIALS AND METHODS ETHICS STATEMENT}

This study was carried out in strict accordance with the recommendations in the Guidance for the Care and Use of Laboratory Animals of the National Institutes of Health. All experimental protocols were approved by the Swiss animal experimentation authorities (Service de la consommation et des affaires vétérinaires, Chemin des Boveresses 155, 1066 Epalinges, Switzerland, permit number: 2301). Every effort was made to minimize the number of animals used and their suffering.

\section{EXPERIMENTAL ANIMALS}

Animals used for the study were adult males of 6 weeks of age at the beginning of the experiment. All animals were housed in standard cages under a 12-h light/dark cycle and temperaturecontrolled $\left(22^{\circ} \mathrm{C}\right)$ conditions. Food and water were available ad libitum. $\mathrm{C} 57 \mathrm{Bl} / 6$ mice were purchased from Janvier (le Genest Saint Isle, France), GFAP-GFP mice were a kind gift from the laboratory of Helmut Kettenmann (Max-Delbruck center, Berlin, Germany) (Nolte et al., 2001). They express the green fluorescent protein (GFP) under the control of the astrocyte-specific human GFAP promoter. Nestin-GFP mice were a kind gift from the laboratory of K. Mori (PRESTO, Kyoto, Japan) (Yamaguchi et al., 2000). They express GFP under the control of the stem cell-specific promoter nestin. Food pellets containing 40-ppm of Dox were purchased from Harlan Laboratory (WI, USA). Control mice were fed with the same food pellets without Dox, purchased from the same source.

\section{BrdU ADMINISTRATION}

Bromodeoxyuridine (BrdU, Sigma-Aldrich, Buchs, Switzerland) was injected intraperitoneally at doses of $100 \mathrm{mg} / \mathrm{kg}$ in saline, 3 times at 2-h intervals. Mice were then sacrificed either $2 \mathrm{~h}$ after the last injection, to examine cell proliferation (Mandyam et al., 2007; Taupin, 2007; Yang et al., 2011; Gao and Chen, 2013) or 30 days after injections, to examine newborn cells survival (Taupin, 2007).

\section{RETROVIRUS-MEDIATED LABELING}

We used a retroviral vector derived from the Moloney murine leukemia virus (MoMuLv) containing a GFP-expression cassette under the control of the cytomegalovirus early enhancer and chicken beta-actin promoter (cag) (Zhao et al., 2006). The final virus titer was $10 \mathrm{E} 8 \mathrm{pfu} / \mathrm{ml}$, as measured by GFP-expressing colony formation on $293 \mathrm{~T}$ cells. Mice were anesthetized with a mixture of $90 \mathrm{mg} / \mathrm{kg}$ ketamine and $4.5 \mathrm{mg} / \mathrm{kg}$ xylazine (i.p.) and then placed in a stereotaxic instrument (Narishige Scientific Instruments, Tokyo, Japan). $1.5 \mu$ l of virus was injected bilaterally at the following coordinates from the Bregma: anteroposterior $-2 \mathrm{~mm}$, lateral $1.75 \mathrm{~mm}$ and dorsoventral $-2.25 \mathrm{~mm}$. GFP signal was amplified by immunohistochemistry using chicken antiGFP IgY (AnaSpec Inc. CA 94555, 1:1000) and dylight 488 goat anti-chicken IgY (Jackson ImmunoResearch Europe ltd., Suffolk, United Kingdom; 1:250).

\section{TISSUE COLLECTION AND PREPARATION}

Mice were deeply anesthetized with a lethal dose of pentobarbital (10 mL/kg, Sigma-Aldrich, Buchs, Switzerland) and perfusionfixed with $50 \mathrm{ml}$ of $0.9 \%$ saline immediately followed by $100 \mathrm{~mL}$ of $4 \%$ paraformaldehyde (Sigma-Aldrich, Switzerland) dissolved in phosphate buffer saline (PBS 0.1 M, pH 7.4). Brains were then dissected, post-fixed overnight at $4^{\circ} \mathrm{C}$, cryoprotected $24 \mathrm{~h}$ in $30 \%$ sucrose and rapidly frozen. Coronal frozen sections of a thickness of $40 \mu \mathrm{m}$ were cut with a microtome-cryostat (Leica MC $3050 \mathrm{~S}$ ) and slices were stored in cryoprotectant (30\% ethylene glycol and $25 \%$ glycerin in $1 \mathrm{X}$ PBS) at $-20^{\circ} \mathrm{C}$ until processing for immunostaining, as described previously (Thuret et al., 2009).

\section{IMMUNOHISTOCHEMISTRY}

Sections were washed 3 times in PBS $0.1 \mathrm{M}$. BrdU detection required formic acid pretreatment (formamide $50 \%$ in $2 \times$ SSC buffer; $2 \times \mathrm{SSC}$ is $0.3 \mathrm{M} \mathrm{NaCl}$, and $0.03 \mathrm{M}$ sodium citrate, $\mathrm{pH} 7.0$ ) at $65^{\circ} \mathrm{c}$ for $2 \mathrm{~h}$ followed by DNA denaturation for $30 \mathrm{~min}$ in $2 \mathrm{M}$ $\mathrm{HCl}$ at $37^{\circ} \mathrm{C}$ and rinsed in $0.1 \mathrm{M}$ borate buffer $\mathrm{pH} 8.5$ for $10 \mathrm{~min}$. Nonspecific binding was blocked with $0.25 \%$ Triton-X100 and $15 \%$ normal serum [normal goat serum (Gibco, 16210-064) or normal donkey serum (Sigma Aldrich, D-9663), depending on the secondary antibody] in PBS 0.1 M. Slices were then incubated $48 \mathrm{~h}$ at $4^{\circ} \mathrm{C}$ with the primary antibodies described below. Then sections were incubated for $2 \mathrm{~h}$ with the corresponding secondary antibodies in PBS 0.1 M. 4,6 diamidino-2-phenylindole (DAPI) was used to reveal nuclei.

Primary antibodies used for immunohistochemistry were as follows: rabbit anti-Ki-67 (1:200, Abcam, ab15580), goat antiDCX (1:500, Santa Cruz biotechnology, sc-8066), rabbit antiTbr2 (1:200, Abcam, ab23345), mouse monoclonal anti-BrdU (1:250, Chemicon International, Dietikon, Switzerland), mouse anti-NeuN (Chemicon international 1:1000), goat anti-Ibal (1:200, Abcam, ab5076), rabbit anti-GFAP (1:500, Invitrogen, 180063).

Secondary antibodies were used as follows: goat anti-mouse Alexa-594 (1:250, Invitrogen), goat anti-rabbit Alexa-594 (1:250, Invitrogen), goat anti-rabbit Alexa-488 (1:250, Invitrogen), donkey anti-goat Alexa-555 (1:250, Invitrogen).

\section{IMAGE ANALYSIS}

All images were acquired using a confocal microscope (Zeiss LSM 710 Quasar Carl Zeiss, Oberkochen, Germany). The total numbers of immunoreactive cells throughout the entire granule cell layer were estimated using stereological sampling, as previously described (Thuret et al., 2009), between -1.3 and $-2.9 \mathrm{~mm}$ from the Bregma. However, no guard zones were used, which may lead to possible bias in the counting of cells at the edge of each section, spread across control and Dox groups. For each animal, a 1-in6 series of sections was stained with the nucleus marker DAPI and used to measure the volume of the granule cell layer. The granule cell area was traced using Axiovision (Zeiss, Germany) software and the granule cell volume was determined by multiplying the traced granule cell layer area by the thickness of the corresponding section and the distance between the sections sampled $(240 \mu \mathrm{m})$. For all mice analyzed in this study, no difference was found between Dox-treated and control animals. All 
cells were counted blind with regard to the mouse status. Cells were counted in the entire thickness of the sections in a 1-in-6 series of section $(240 \mu \mathrm{m}$ apart) with a $40 \times$ objective. The number of immunolabeled cells was then related to granule cell layer sectional volume and multiplied by the reference volume to estimate the total number of immunolabeled cells. Cells expressing BrdU, Ki-67, DCX or Tbr2 were counted in the granule cell layer, whereas cells expressing Ibal and GFAP (Figure 6) were counted in the whole DG.

BrdU colocalization with the neuronal marker NeuN was analyzed by confocal microscopy and was confirmed on single optical sections, for 50-60 cells per animal. The proportion of doublelabeled cells was then obtained for each animal and then averaged for each group. DCX-expressing cells were counted on confocal stack images using the colocalization with the nuclear stain DAPI and/or the presence of processes as visual landmarks for their identification. This approach may lead to a slight underestimation of DCX-expressing cell numbers. Spine density was assessed as previously described (Krzisch et al., 2013). Dendrites were imaged with confocal microscopy in the second third of the molecular layer and their length as well as spine density (number of spines divided by dendritic length) was measured using image J software, for 40-50 neurons per group.

Spine morphology was classified in three groups based on the maximal diameter of the spine head, as measured on maximal projections with Image J software: Filopodia $<0.25 \mu \mathrm{m}$, thin spines $0.25-0.45 \mu \mathrm{m}$ and mushroom spines $>0.45 \mu \mathrm{m}$. The percentage of each type of dendritic spine was then expressed by neuron and averaged for each mouse (25-30 neurons per group, 800 spines per group).

\section{CELL CULTURE}

Adult neural progenitor cells (NPC) expressing the red fluorescent protein (RFP) are a kind gift from the laboratory of Fred Gage (Salk Institute, San Diego, USA). They were originally isolated from the DG of adult Fisher 344 rats and cultured as previously described (Palmer et al., 1997).

Microglia and astrocyte primary culture were purified from postnatal day 2 rats. Cerebral cortices were mechanically triturated for homogenization and seeded onto poly-D-lysine coated $75 \mathrm{~cm}^{2}$ flasks in Dulbecco's Modified Eagle Medium (DMEM) glutamax (Invitrogen, USA), 10\% normal calf serum with penicillin/streptomycin (Invitrogen, USA). Cells were grown for 5-7 days in a humidified $5 \% \mathrm{CO} 2$ incubator at $37^{\circ} \mathrm{C}$. At confluence, flasks were shaken at $250 \mathrm{rpm}$ on an orbital shaker for $2 \mathrm{~h}$ to separate microglia from astrocytes. Detached microglia were seeded in poly-D-lysine coated 6-well microplates in culture medium supplemented with $30 \%$ astrocyte conditioned medium.

All three cell types were cultured separately and, one day after plating, were treated with Dox or vehicle (PBS). Dox was purchased from Sigma-Aldrich (St Louis, MO, USA) and dissolved in PBS to prepare a stock solution of $10 \mathrm{mg} / \mathrm{ml}$. The stock solution was stored at $-20^{\circ} \mathrm{C}$. Upon use, the stock solution was diluted 10 times in PBS and $1 \mu \mathrm{l}$ of the solution was added daily to the culture medium, at a concentration of $1 \mu \mathrm{g} / \mathrm{ml}$. This regimen of Dox treatment is commonly used for the induction of tetracycline-dependent gene expression in cell culture (Stegmeier et al., 2005; Richter et al., 2013).

After the treatment, cells were fixed and mounted for cell quantification. The number of Ibal,$+ \mathrm{RFP}+$, and GFAP + cells was counted in twelve randomly selected fields per condition (three culture wells per groups, four fields per culture well) on confocal micrographs. The number of cells was then divided by the surface area of the selected fields, to obtain cell density. The density was then averaged between the four fields to obtain the average density per culture well.

\section{STATISTICAL ANALYSIS}

Hypothesis testing was two-tailed. All analyses were performed using JMP10 software. First, Shapiro-Wilk tests were performed on each group of data to test for distribution normality. The distribution was normal for all data. For two-sample comparisons, the equality of variances of the groups was tested and the adequate unpaired $t$-test was used. For the analysis of dendritic spine morphology (Figure 5C), parametric tests were used (twoway ANOVA followed by a post-hoc Student's $t$-test). Data are presented as mean \pm SEM.

\section{RESULTS}

\section{Dox EXPOSURE INCREASED CELL PROLIFERATION}

To examine the effect of Dox treatment on cell proliferation, 6 weeks old $\mathrm{C} 57 \mathrm{Bl} / 6$ mice were fed for 4 weeks with unlimited supply of food pellets containing either $40 \mathrm{ppm}$ of Dox or no Dox (Figure 1A). At the end of the treatment, mice were sacrificed and brain slices were immunostained for the proliferation marker Ki67 (Kee et al., 2002). Treated animals showed a higher number of Ki-67 labeled cells in the granule cell layer of the DG than control mice (Figures 1B,C, Student's $t$ - test, $p<0.001$ ) suggesting an increased number of cells in the cell cycle.

We next examined the effect of Dox treatment on immature neurons expressing DCX. Dox treatment significantly increased the number of immature neurons (Figures 1D,E, Student's $t$ test, $p<0.001)$. Thus, Dox treatment enhanced proliferation in the adult hippocampus and increased the number of immature neurons. To test whether the increased number of Ki-67- and DCX-expressing cells could be caused by a change in hippocampal volume upon Dox treatment, we measured the volume of the granule cell layer of all mice. We did not detect a difference between treated and untreated animals $\left(0.16 \pm 0.05 \mathrm{~mm}^{3}\right.$ vs. $0.15 \pm 0.01 \mathrm{~mm}^{3}$, respectively, $n=5$ and Student's $t$-test, $p=$ 0.7 ), indicating that the increased number of Ki-67 and DCXimmunolabeled cells reflected an increase in proliferation.

We then investigated the effect of Dox on the two main types of proliferative cells: RGL cells and TAPs. RGL cells were identified using nestin-GFP (Figures 2A,B) and GFAP-GFP (Figures 2C,D) mice, which are commonly used mouse models in studies of adult neurogenesis (Huttmann et al., 2003; Mignone et al., 2004; Beckervordersandforth et al., 2010). In both mouse lines, RGL cells are readily identifiable by their specific morphology (Kriegstein and Alvarez-Buylla, 2009), consisting of a nucleus in the SGZ and a large process extending through the granule cell layer and branching into the proximal molecular layer (Figures 2B,D, insets). With immunostaining, we confirmed that 


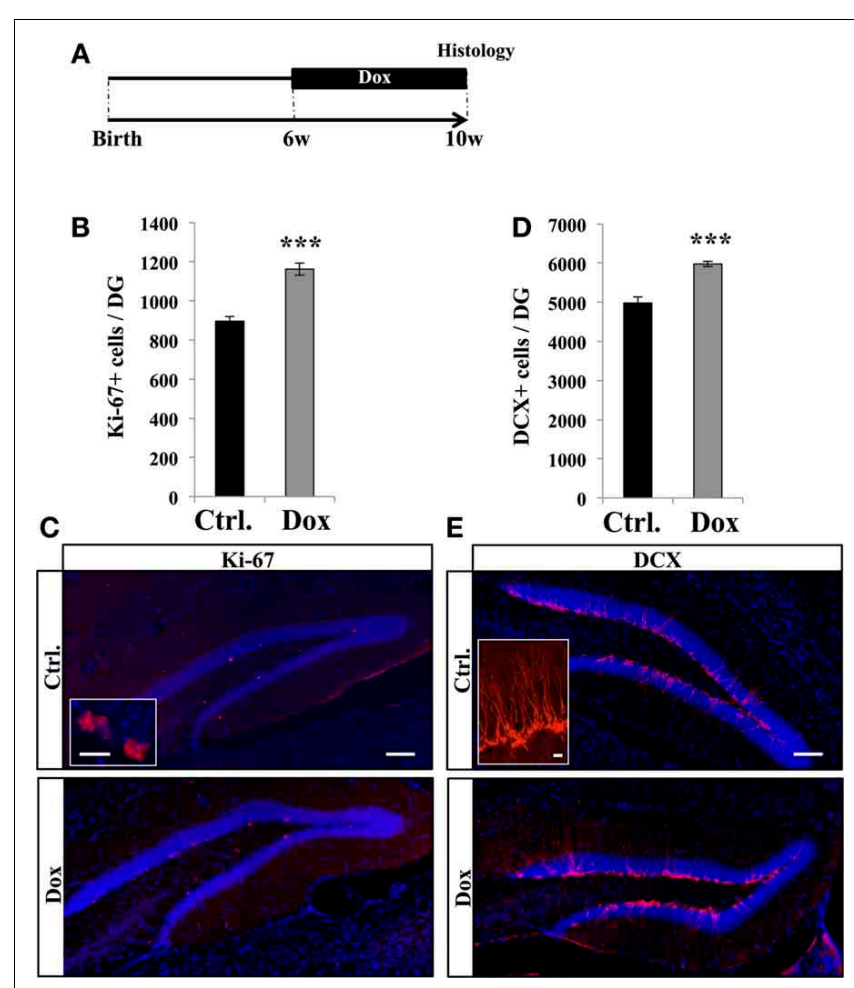

FIGURE 1 | Dox effect on cell proliferation. (A) Experimental timeline: C57BI/6 mice were treated with control food (Ctrl.) or food containing Dox for 4 weeks and sacrificed at 10 weeks of age. (B) Histogram showing the number of Ki-67-expressing cells in the dentate gyrus. Animals: $n=5$ per group. (C) Confocal micrographs of hippocampal sections immunostained with Ki-67 in control animals (upper panel), and treated animals (lower panel). Inset: Higher magnification confocal micrograph of a

Ki-67-expressing cell. (D) Histogram showing the number of doublecortin (DCX)-immunolabeled cells in the dentate gyrus. Animals: $n=5$ per group. (E) Confocal micrographs of hippocampal sections immunostained for DCX from control animals (upper panel), and treated animals (lower panel). Inset: Higher magnification confocal micrograph of a DCX-immunolabeled group of cells. Blue: Dapi staining. Scale bars: $100 \mu \mathrm{m}$, insets $10 \mu \mathrm{m},{ }^{* * *} p<0.001$ bilateral Student's $t$-test. Each value represents the mean \pm SEM.

these cells expressed nestin, GFAP, and sox-2 (data not shown). Surprisingly, Dox treatment significantly reduced the number of RGL cells in both the nestin-GFP mice (Figure 2A, Student's $t$ test, $p<0.001$ ) and the GFAP-GFP mice (Figure 2C, Student's $t$-test, $p<0.001)$.

TAPs were identified using immunostaining against Tbr2, (Hodge et al., 2008, Figure 3). In untreated nestin-GFP mice, $94.5 \pm 1 \%$ of TbR2 + cells co-labeled with GFP $(n=100$ Tbr $2+$ cells), but $93.1 \pm 2 \%$ of them did not have RGL morphology (Figure 3C). Dox treatment significantly increased the number of Tbr2-expressing cells (Figure 3A, Student's $t$-test, $p<0.001$ ). Here too, we did not detect any difference in the volume of the granule cell layer between treated and control animals in both nestin-GFP treated and untreated animals $\left(1.4 \pm 0.09 \mathrm{~mm}^{3}\right.$ vs. $1.51 \pm 0.06 \mathrm{~mm}^{3}$, respectively, $n=4$ and Student's $t$-test, $p=0.63)$ and treated and untreated GFAP-GFP mice $(1.43 \pm$ $0.04 \mathrm{~mm}^{3}$ vs. $1.43 \pm 0.01 \mathrm{~mm}^{3}$, respectively, $n=4$ and Student's $t$-test, $p=0.97)$.

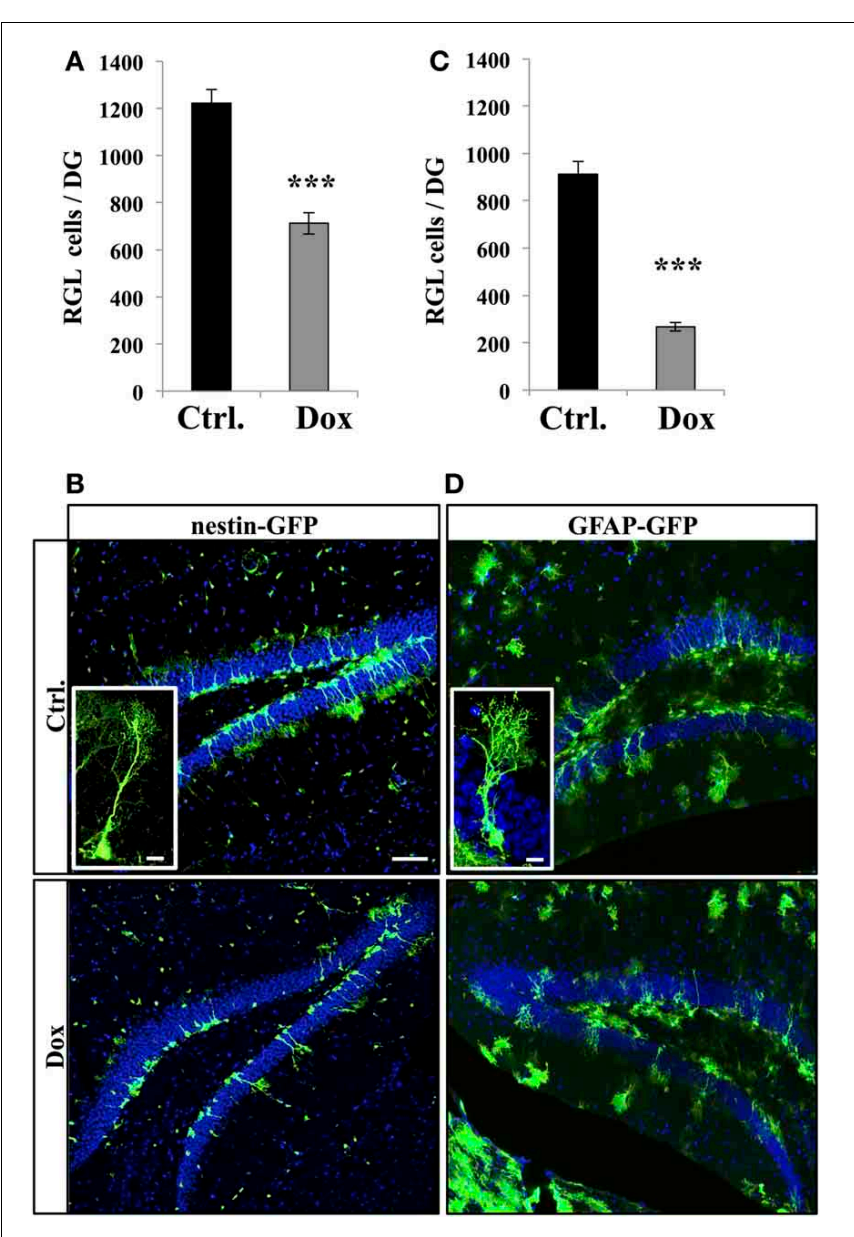

FIGURE 2 | Dox effect on the number of RGL cells in the dentate gyrus. (A) Histogram showing the number of RGL cells in the dentate gyrus of nestin-GFP mice exposed to control (Ctrl.) or Dox treatment. (B) Confocal micrographs of hippocampal sections from control (upper panel) and treated animals (lower panel). Inset: higher magnification confocal micrograph of a RGL cell. (C) Histogram showing the number of RGL cells in the dentate gyrus of GFAP-GFP mice exposed to control (Ctrl.) or Dox treatment. (D) Confocal micrographs of hippocampal sections from control (upper panel) and treated animals (lower panel). Inset: higher magnification confocal micrograph of a RGL cell. Blue: Dapi staining. Animals: $n=4$ per group, scale bars: $100 \mu \mathrm{m}$, insets $10 \mu \mathrm{m},{ }^{* * *} p<0.001$ bilateral Student's $t$-test. Each value represents the mean \pm SEM.

Thus, Dox treatment increased the total number of the highlyproliferative progenitors, but decreased the number of the quiescent, slowly-proliferative RGL cells.

\section{Dox TREATMENT INCREASED ADULT NEUROGENESIS}

To examine the effect of Dox treatment on the fate of newborn cells, two groups of adult $\mathrm{C} 57 \mathrm{Bl} / 6$ mice were treated with Dox during 4 weeks, after which they received three injections of BrdU (intraperitoneal, $1.0 \mathrm{mg} / \mathrm{kg}$ in saline at $2 \mathrm{~h}$ intervals). One group of mice was sacrificed $2 \mathrm{~h}$ after the last injection, while the second group received another 4 weeks of Dox treatment and was analyzed thereafter to assess neuronal differentiation (Figure 4A). The first group showed a higher number of BrdUexpressing cells in the DG as compared to control-treated mice 


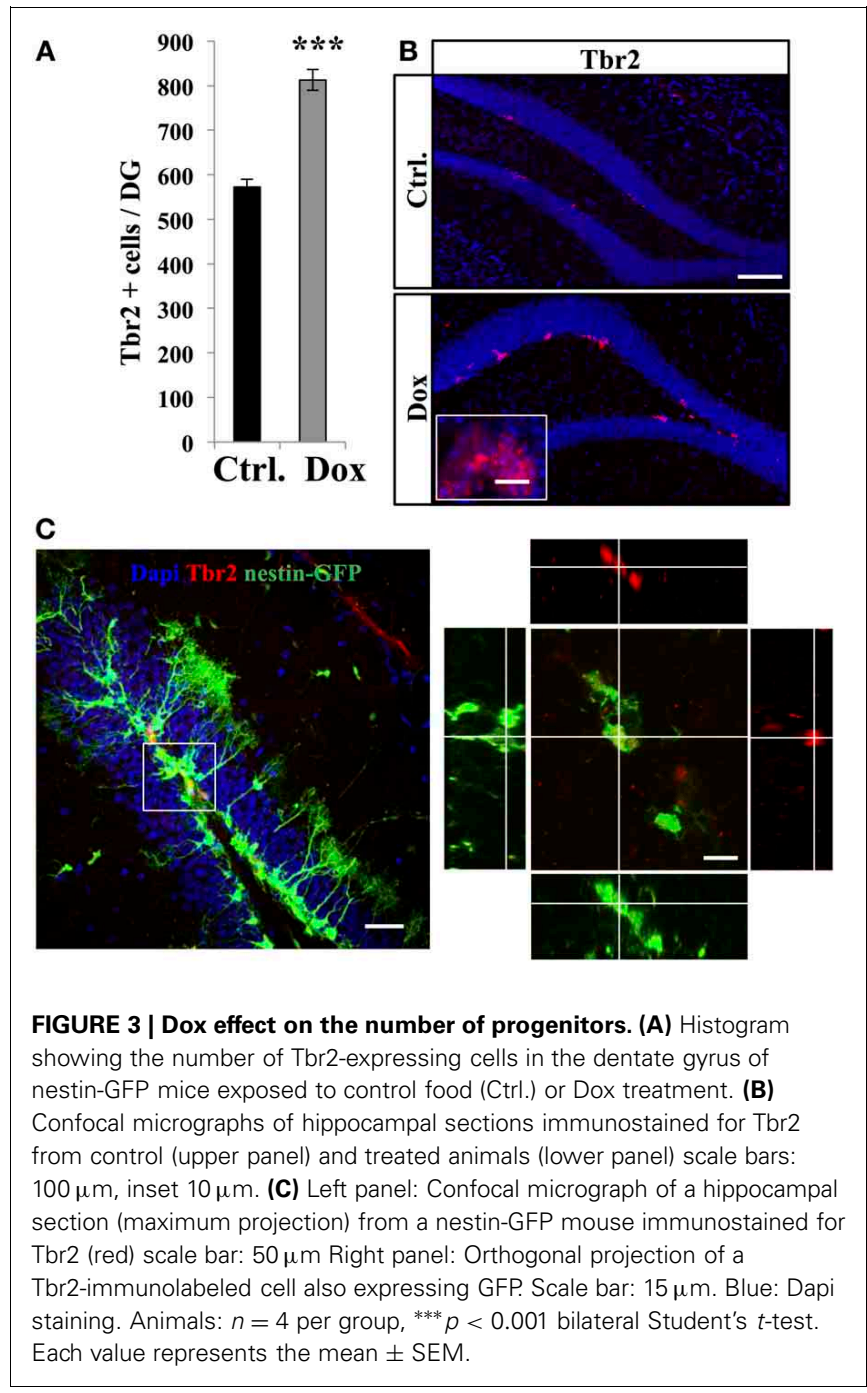

(Figure 4B, Student's $t$-test, $p<0.01$ ), supporting our previous observation of increased cell proliferation with Dox treatment (Figure 1). Similarly, in the second group (4 weeks after the last BrdU injection), the number of BrdU-expressing cells was higher in Dox-treated mice than in control mice (Figure 4C, Student's $t$-test $p<0.001)$. Finally, we assessed the neuronal differentiation of BrdU-labeled cells into neuronal lineage, by co-labeling for BrdU and the neuron-specific marker, NeuN (Figure 4E). In control mice, neurons accounted for $83 \pm 0.2 \%$ of the surviving BrdU-positive cells as compared to $84 \pm 0.3 \%$ in Dox-treated mice (Student's $t$-test $p>0.05$ ), indicating that differentiation was not affected by Dox treatment. All together, these results indicate that Dox-treated mice generate $43.4 \pm 0.4 \%$ more neurons than non-treated mice (Figure 4D, Student's $t$-test, $p<0.001)$.

\section{DOX TREATMENT INCREASED SPINE DENSITY ON NEWBORN NEURONS}

The final stage of neurogenesis consists in the integration of the newly-formed neurons into the hippocampal excitatory circuitry

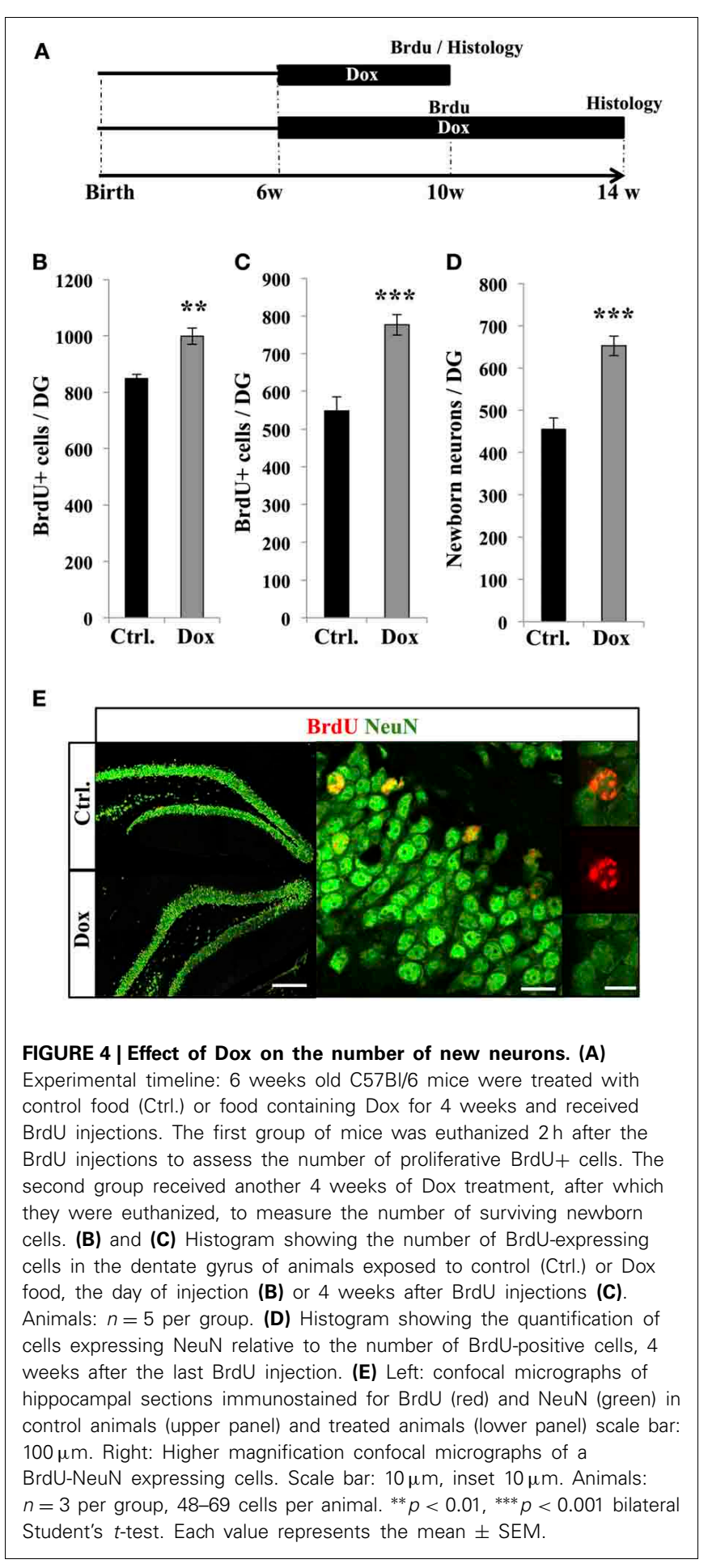

and is commonly assessed by measuring dendritic spine density. To this aim, new neurons were identified by viral-mediated gene transfer, with the use of a MoMuLV containing the expression cassette for GFP. C57Bl/6 mice were treated with Dox for 4 weeks and then stereotaxically injected with GFP-retrovirus, followed by 4 weeks of Dox treatment (Figure 5A). Dendritic spines were analyzed in the middle-third of the molecular layer, where inputs arise mainly from the entorhinal cortex. 
At 30 days post-virus infection, Dox treatment increased spine density (Figures 5B,D,E, Student's $t$-test, $p<0.001$ ). Dendritic spine diameter increases with neuronal maturation (Zhao et al., 2006; Toni et al., 2007) and reflects synaptic strength (Murthy et al., 2001). To examine the effect of Dox on dendritic spine maturation, we classified dendritic spines in three categories, based on the maximal diameter of the spine head: filopodia spines $<0.25 \mu \mathrm{m}$, thin spines $0.25-0.45 \mu \mathrm{m}$ and mushroom spines $>0.45 \mu \mathrm{m}$. Dox treatment did not change the proportion of filopodia, thin and mushroom spines [Figure 5C, two way ANOVA $F_{(2,108)}=1.1, p=0.33$ ], indicating that this treatment increased spine density but did not affect dendritic spine morphology.

\section{Dox REDUCED MICROGLIA BUT NOT ASTROGLIA in vivo AND in vitro}

Dox is a member of the tetracycline antibiotics group and its analog, minocycline, has been reported to decrease microglia and inhibit microglia activation (Ng et al., 2012). We therefore

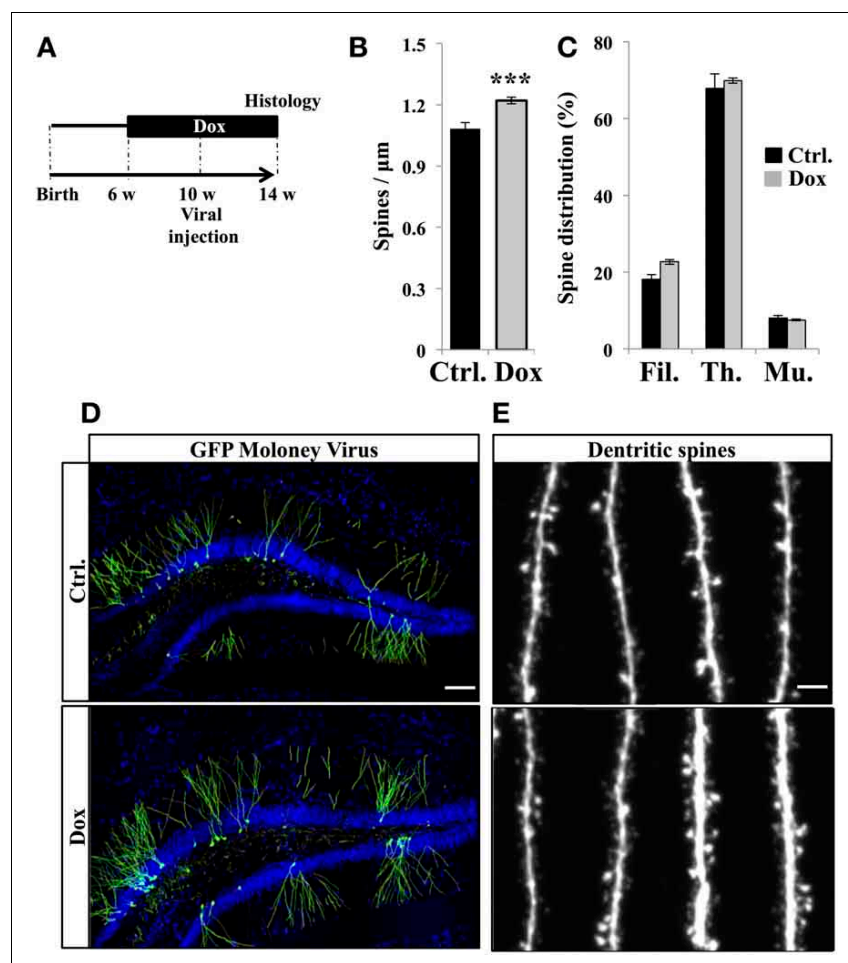

FIGURE 5 | Effect of Dox on the spine density of newborn neurons. (A) Experimental timeline: C57BI/6 mice were treated with control food (Ctrl.) or food containing Dox for 4 weeks before viral injection. Dox treatment was continued for 4 weeks after viral injection. (B) Histogram showing the spine density on newborn neurons from the two experimental conditions, $n=48-54$ neurons per group, ${ }^{* * *} p<0.001$ bilateral Student's $t$-test. (C) Histogram showing the percentage of filopodia (Fil.), thin spines (Th.), and mushroom spines (Mu.) on newborn neurons from control-treated animals (black) and Dox-treated animals (gray) $n=838-895$ spines per group. (D) Confocal micrographs of hippocampal sections of retrovirally-injected mice from control animals (upper panel) and treated animals (lower panel) Blue: Dapi staining, scale bar: $100 \mu \mathrm{m}$. (E) Confocal micrographs of spiny dendrites from control animals (upper panel) and treated animals (lower panel) scale bars: $10 \mu \mathrm{m}$. Each value represents the mean \pm SEM. analyzed the effect of Dox on microglia, identified with immunostaining for the microglia-specific marker Iba1. Four weeks of Dox treatment significantly decreased the number of Iba1-expressing cells in the hippocampus (Figures 6A,B, Student's $t$-test, $p<$ $0.001)$. In contrast, the number of astrocytes, identified with immunohistochemistry for GFAP, was not affected by Dox treatment (Figures 6C,D, Student's $t$-test, $p=0.59$ ), indicating that the effect of Dox was specific to microglia. To test the effect of Dox directly on microglia, we performed in vitro experiments on purified cell cultures. Microglia was treated with either $1 \mu \mathrm{g} / \mathrm{ml}$ Dox or the equivalent volume of PBS $0.1 \mathrm{M}$. After 8 days, cells were fixed and immunostained for Iba1. Dox treatment reduced the density of microglia (Figures 7A,B, Student's $t$-test, $p<0.01$ ). In contrast, the same treatment did not have any effect on purified astrocytes identified with GFAP immunostaining (Figures 7C,D, Student's $t$-test, $p=0.2$ ) or on NPC (Figures 7E,F, Student's $t$-test, $p=0.26$ ). Thus, Dox treatment reduced microglia both in vivo and in vitro.

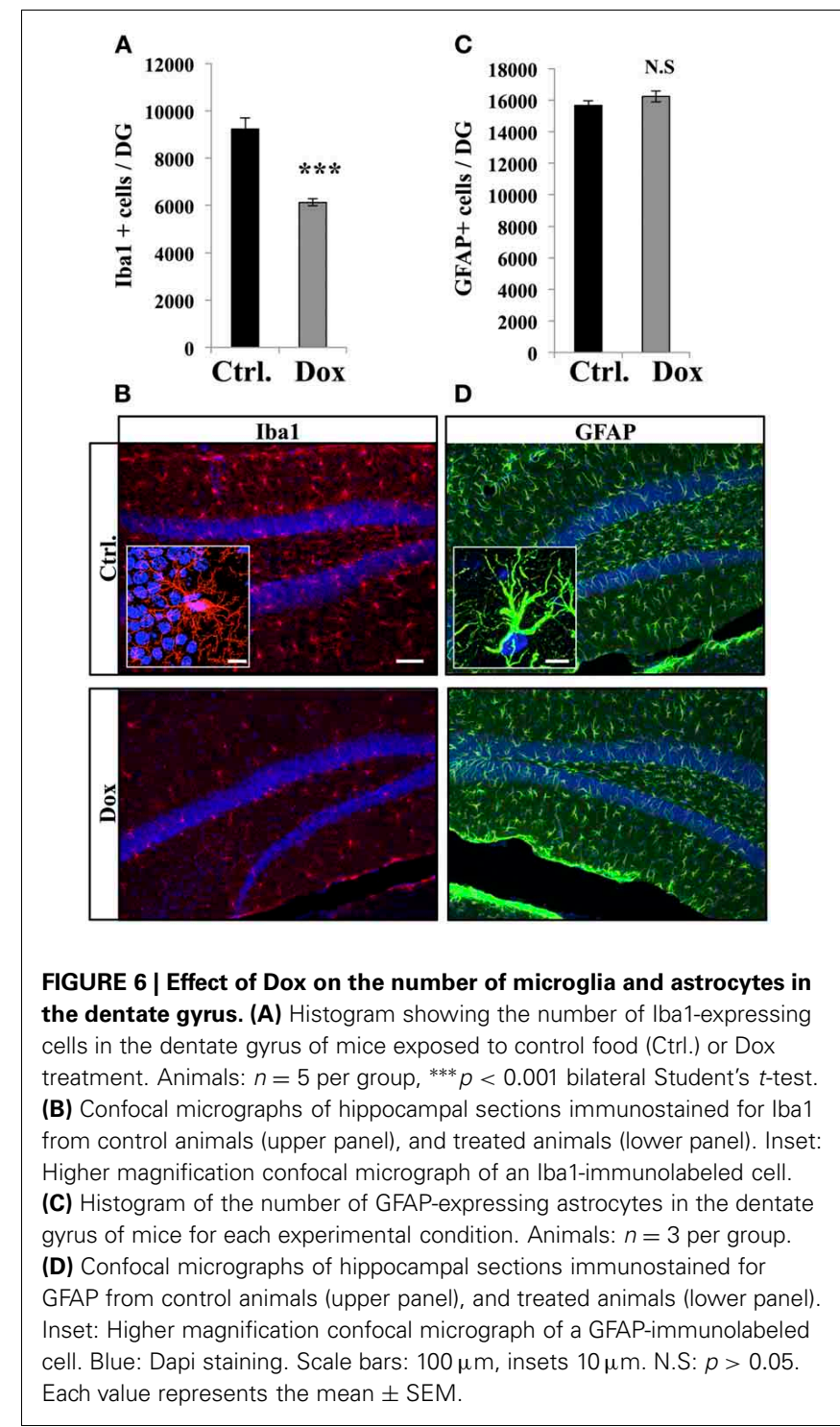




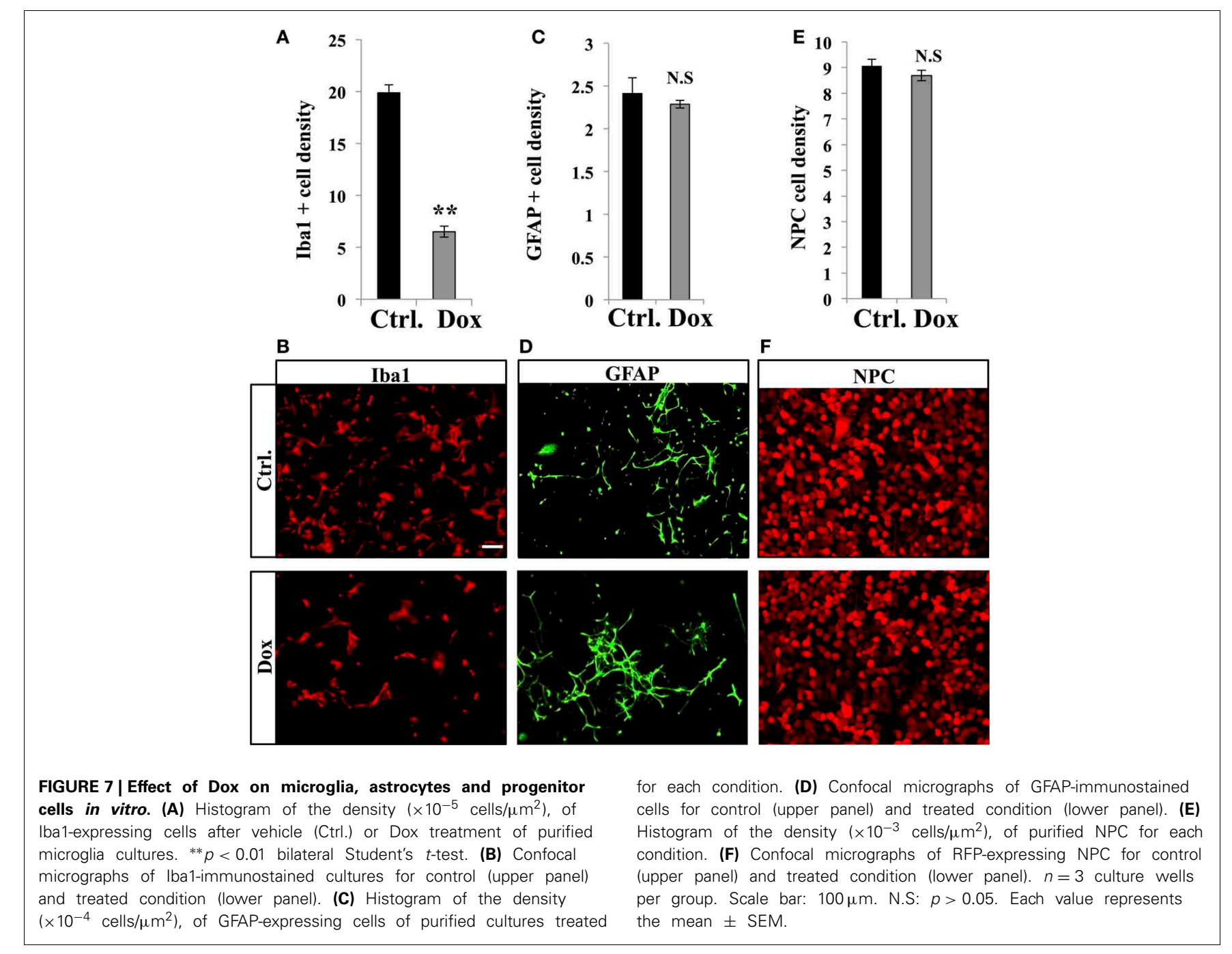

\section{DISCUSSION}

In this study, we tested the effect on adult neurogenesis of a Dox treatment commonly used to regulate gene expression in inducible transgenic mice. Dox reduced the number of RGL cells but increased the number of TAPs in the DG of adult mice. This may result from a shift in fate choice of the RGL cells leading to a depletion of the RGL cells pool in favor of the highly proliferative TAPs (Encinas et al., 2011), a possibility which may be further tested by examining the expression of the proliferation marker Ki-67 and self-renewal transcription factor sox2 in RGL cells of both groups. As a consequence, Dox treatment increased cell proliferation and resulted in a net increase in neurogenesis. Although cell counts were performed without the use of guard zones, which may lead to possible bias in the counting of cells at the edge of each section, this bias was spread across both groups and may affect the absolute number of cells, but not the intergroup difference. In addition, Dox increased dendritic protrusions density on the neurons formed during the treatment. Concomitantly, microglia but not astrocytes were reduced by Dox. These results indicate that Dox has multiple effects on adult neurogenesis.
Although the mechanism of action of Dox is unclear, the dramatic reduction of microglia in vitro and in vivo, and the lack of effect of Dox on astrocytes and NPC in vitro, raises the possibility that the effect of this drug on adult neurogenesis may be mediated by microglia. In support of this possibility, inflammatory microglia inhibit adult neurogenesis (Monje et al., 2002; Ekdahl et al., 2003; Liu et al., 2007; Kohman et al., 2012) and the exerciseinduced increase and the age-dependent decline in neurogenesis are mediated by microglia, possibly through CX3CR1-receptor activity (Vukovic et al., 2012). Furthermore, Dox and its analog minocycline have been shown to inhibit inflammation in models of ischemia, brain trauma, pain or neurodegenerative diseases (Yrjanheikki et al., 1998; Thomas et al., 2003; Buller et al., 2009; Kim and Suh, 2009; Jantzie and Todd, 2010; Lu et al., 2010; Wideroe et al., 2012; Kobayashi et al., 2013). Accordingly, minocycline decrease microglia number and increase adult neurogenesis (Kohman et al., 2013). Thus, an extensive reduction in microglia, such as observed with Dox treatment, may interfere with adult neurogenesis. However, the effects of Dox on microglia and neurogenesis may be unrelated and further experiments will 
be necessary to examine the causality between reduced microglia and increased neurogenesis upon Dox treatment.

In addition to its effect on microglia, Dox is known to also inhibit Matrix Metalloproteinases (MMPs) (Burggraf et al., 2007; Lee et al., 2009). MMPs are soluble or membrane-bound proteases capable of degrading cell-surface receptors and extracellular matrix proteins, which play a role in tissue remodeling and receptor activation. MMPs are involved in several aspects of neurogenesis: MMP-17 prevents neurogenesis by shedding the ligand for, and activating EGFR (Epidermal growth factor receptor) and its inhibition results in increased neurogenesis (Romero-Grimaldi et al., 2011). MMP-3 and MMP-9 promote the differentiation and migration of neural progenitors (Barkho et al., 2008). Also, MMPs are involved in synaptic plasticity (Bozdagi et al., 2007) and synaptogenesis (Ethell and Ethell, 2007) by the cleavage of trans-synaptic adhesion molecules (Huntley, 2012; Peixoto et al., 2012) and the inhibition of MMP-9 inhibits the LTP-induced spine enlargement and stabilization (Wang et al., 2008). Finally, MMPs are involved in inflammation and the genetic deletion of MMP-9 results in decreased inflammation and neuroprotection in a mouse model of hypoxia (Svedin et al., 2007). Thus, the inhibition of MMPs by Dox may result in increased neurogenesis. However, the involvement of MMPs or microglia on the Doxmediated increase in neurogenesis remains unclear and additional experiments may elucidate the mode of action of Dox.

Together, our observations indicate that Dox decreased microglia and increased adult neurogenesis, a combination of effects that can introduce confounding factors in studies of adult neurogenesis or brain inflammation. Together with the recent observation that Dox reduced alcohol consumption in mice and increased the sensitivity to alcohol-induced motor impairment (McIver et al., 2012), the present study suggests that, at doses necessary for the induction of gene expression in transgenic mice with tetracycline-responsive promoters, Dox has multiple

\section{REFERENCES}

Altman, J. (1969). Autoradiographic and histological studies of postnatal neurogenesis. 3. Dating the time of production and onset of differentiation of cerebellar microneurons in rats. J. Comp. Neurol. 136, 269-293. doi: $10.1002 / \mathrm{cne} .901360303$

Barkho, B. Z., Munoz, A. E., Li, X., Li, L., Cunningham, L. A., and Zhao, X. (2008). Endogenous matrix metalloproteinase (MMP)-3 and MMP9 promote the differentiation and migration of adult neural progenitor cells in response to chemokines. Stem Cells 26, 3139-3149. doi: 10.1634/stemcells.2008-0519

Beckervordersandforth, R., Tripathi, P., Ninkovic, J., Bayam, E., Lepier, A., Stempfhuber, B., et al. (2010). In vivo fate mapping and expression analysis reveals molecular hallmarks of prospectively isolated adult neural stem cells. Cell Stem Cell 7, 744-758. doi: 10.1016/j.stem.2010.11.017
Bozdagi, O., Nagy, V., Kwei, K. T., and Huntley, G. W. (2007). In vivo roles for matrix metalloproteinase- 9 in mature hippocampal synaptic physiology and plasticity. J. Neurophysiol. 98, 334-344. doi: 10.1152/jn.00202.2007

Buller, K. M., Carty, M. L., Reinebrant, H. E., and Wixey, J. A. (2009). Minocycline: a neuroprotective agent for hypoxic-ischemic brain injury in the neonate? J. Neurosci. Res. 87, 599-608. doi: 10.1002/jnr.21890

Burggraf, D., Trinkl, A., Dichgans, M., and Hamann, G. F. (2007). Doxycycline inhibits MMPs via modulation of plasminogen activators in focal cerebral ischemia. Neurobiol. Dis. 25, 506-513. doi: 10.1016/j.nbd.2006.10.013

Cho, Y., Son, H. J., Kim, E. M., Choi, J. H., Kim, S. T., Ji, I. J., et al. (2009). Doxycycline is neuroprotective against nigral dopaminergic degeneration by a dual mechanism

effects on the central nervous system. Further experiments will be needed to determine whether shorter Dox treatments or other routes of administration, such as intraperitoneal injections, or administration in water induce similar effects on adult neurogenesis and microglia. However, the best experimental design to circumvent the caveats of using tetracycline-responsive promoters relies on the appropriate use of Tet-on or Tet-off systems to enable the experimental tests to be performed in absence of Dox. Alternatively, it is recommended that control experiments include Dox-treated animals. Gene expression control is a critical and increasingly used tool for our understanding of brain physiology and future developments will enable the use of this technology with more specific approaches, thereby reducing confounding factors. In this perspective, the recent introduction of new Tet activators with enhanced sensitivity to Dox represents an interesting effort aimed at using lower doses of Dox, thereby reducing effects on brain physiology (Zhou et al., 2006).

\section{AUTHOR CONTRIBUTIONS}

Conceived and designed the experiments: Sebastien Sultan, Elias Gebara, and Nicolas Toni. Performed the experiments: Elias Gebara, Sebastien Sultan. Analyzed the data: Sebastien Sultan and Elias Gebara. Wrote the paper: Sebastien Sultan, Elias Gebara, and Nicolas Toni.

\section{ACKNOWLEDGMENTS}

The authors wish to thank Romain Gosselin (Department of Fundamental Neurosciences, University of Lausanne, Switzerland) for critical insight on in vitro experiments and Coralie Rummel and Florian Udry for technical assistance. Images acquisition was performed at the Cellular Imaging Facility of the university of Lausanne (Lausanne, Switzerland). This work was supported by the Swiss National Science Foundation.

involving MMP-3. Neurotox. Res. 16, 361-371. doi: 10.1007/s12640-0099078-1

Chow, J. D. Y., Price, J. T., Bills, M. M., Simpson, E. R., and Boon, W. C. (2012). A doxycycline-inducible, tissue-specific aromatase-expressing transgenic mouse. Transgenic Res. 21, 415-428. doi: 10.1007/s11248011-9525-7

Clark, W. M., Lessov, N., Lauten, J. D., and Hazel, K. (1997). Doxycycline treatment reduces ischemic brain damage in transient middle cerebral artery occlusion in the rat. J. Mol. Neurosci. 9, 103-108. doi: 10.1007/BF02736854

Dupret, D., Fabre, A., Döbrössy, M. D., Panatier, A., Rodríguez, J. J., Lamarque, S., et al. (2007). Spatial learning depends on both the addition and removal of new hippocampal neurons. PLoS Biol. 5:e214. doi: 10.1371/journal.pbio.0050214

Ehninger, D., and Kempermann, G. (2008). Neurogenesis in the adult hippocampus. Cell Tissue Res. 331, 243-250. doi: 10.1007/s00441-0070478-3

Ekdahl, C. T., Claasen, J. H., Bonde, S., Kokaia, Z., and Lindvall, O. (2003). Inflammation is detrimental for neurogenesis in adult brain. Proc. Natl. Acad. Sci. U.S.A. 100, 13632-13637. doi: 10.1073/pnas. 2234031100

Encinas, J. M., Michurina, T. V., Peunova, N., Park, J. H., Tordo, J., Peterson, D. A., et al. (2011). Division-coupled astrocytic differentiation and age-related depletion of neural stem cells in the adult hippocampus. Cell Stem Cell 8, 566-579. doi: 10.1016/j.stem. 2011.03.010

Ethell, I. M., and Ethell, D. W. (2007). Matrix metalloproteinases in brain development and remodeling: synaptic functions and targets. J. Neurosci. Res. 85, 2813-2823. doi: 10.1002/ jnr.21273 
Gage, F. H. (2000). Mammalian neural stem cells. Science 287, 1433-1438. doi: $10.1126 /$ science.287.5457.1433

Gao, X., and Chen, J. (2013). Moderate traumatic brain injury promotes neural precursor proliferation without increasing neurogenesis in the adult hippocampus. Exp. Neurol. 239, 38-48. doi: 10.1016/j.expneurol.2012.09.012

Ge, S., Sailor, K. A., Ming, G. L., and Song, H. (2008). Synaptic integration and plasticity of new neurons in the adult hippocampus. J. Physiol. 586, 3759-3765. doi: 10.1113/jphysiol.2008.155655

Gossen, M., and Bujard, H. (1992). Tight control of gene expression in mammalian cells by tetracyclineresponsive promoters. Proc. Natl. Acad. Sci. U.S.A. 89, 5547-5551. doi: 10.1073/pnas.89.12.5547

Gu, Y., Arruda-Carvalho, M., Wang, J., Janoschka, S. R., Josselyn, S. A., Frankland, P. W., et al. (2012). Optical controlling reveals timedependent roles for adult-born dentate granule cells. Nat. Neurosci. 15, 1700-1706. doi: 10.1038/nn.3260

Hodge, R. D., Kowalczyk, T. D., Wolf, S. A., Encinas, J. M., Rippey, C., Enikolopov, G., et al. (2008). Intermediate progenitors in adult hippocampal neurogenesis: $\mathrm{Tbr} 2$ expression and coordinate regulation of neuronal output. J. Neurosci. 28, 3707-3717. doi: 10.1523/JNEUROSCI.4280-07.2008

Huntley, G. W. (2012). Synaptic circuit remodelling by matrix metalloproteinases in health and disease. Nat. Rev. Neurosci. 13, 743-757. doi: 10.1038/nrn3320

Huttmann, K., Sadgrove, M., Wallraff, A., Hinterkeuser, S., Kirchhoff, F., Steinhauser, C., et al. (2003). Seizures preferentially stimulate proliferation of radial glia-like astrocytes in the adult dentate gyrus: functional and immunocytochemical analysis. Eur. J. Neurosci. 18, 2769-2778. doi: 10.1111/j.1460-9568.2003.03002.x

Jantzie, L. L., and Todd, K. G. (2010). Doxycycline inhibits proinflammatory cytokines but not acute cerebral cytogenesis after hypoxia-ischemia in neonatal rats. J. Psychiatry Neurosci. 35, 20-32. doi: 10.1503/jpn.090061

Kee, N., Sivalingam, S., Boonstra, R., and Wojtowicz, J. M. (2002). The utility of Ki-67 and BrdU as proliferative markers of adult neurogenesis. J. Neurosci. Methods 115 , 97-105. doi: 10.1016/S0165-0270 (02)00007-9

Kim, H. S., and Suh, Y. H. (2009). Minocycline and neurodegenerative diseases. Behav. Brain Res. 196, 168-179. doi: 10.1016/j.bbr.2008. 09.040

Kobayashi, K., Imagama, S., Ohgomori, T., Hirano, K., Uchimura, K., Sakamoto, K., et al. (2013). Minocycline selectively inhibits M1 polarization of microglia. Cell Death Dis. 4, e525. doi: 10.1038/cddis.2013.54

Kohman, R. A., Bhattacharya, T. K., Kilby, C., Bucko, P., and Rhodes, J. S. (2013). Effects of minocycline on spatial learning, hippocampal neurogenesis and microglia in aged and adult mice. Behav. Brain Res. 242, 17-24. doi: 10.1016/j.bbr.2012.12.032

Kohman, R. A., Deyoung, E. K., Bhattacharya, T. K., Peterson, L. N., and Rhodes, J. S. (2012). Wheel running attenuates microglia proliferation and increases expression of a proneurogenic phenotype in the hippocampus of aged mice. Brain Behav. Immun. 26, 803-810. doi: 10.1016/j.bbi.2011.10.006

Kriegstein, A., and Alvarez-Buylla, A. (2009). The glial nature of embryonic and adult neural stem cells. Annu. Rev. Neurosci. 32, 149-184. doi: 10.1146/annurev.neuro.051508. 135600

Krzisch, M., Sultan, S., Sandell, J., Demeter, K., Vutskits, L., and Toni, N. (2013). Propofol Anesthesia impairs the maturation and survival of adult-born hippocampal neurons. Anesthesiology 118, 602-610. doi: 10.1097/ALN. 0b013e3182815948

Laplagne, D. A., Espósito, M. S., Piatti, V. C., Morgenstern, N. A., Zhao, C., Van Praag, H., et al. (2006). Functional convergence of neurons generated in the developing and adult hippocampus. PLoS Biol. 4:e409. doi: 10.1371/journal.pbio.0040409

Lee, H., Park, J. W., Kim, S. P., Lo, E. H., and Lee, S. R. (2009). Doxycycline inhibits matrix metalloproteinase9 and laminin degradation after transient global cerebral ischemia. Neurobiol. Dis. 34, 189-198. doi: 10.1016/j.nbd.2008. 12.012

Liu, Z., Fan, Y., Won, S. J., Neumann, M., Hu, D., Zhou, L., et al. (2007). Chronic treatment with minocycline preserves adult new neurons and reduces functional impairment after focal cerebral ischemia. Stroke 38, 146-152. doi: 10.1161/01.STR. 0000251791.64910.cd

Lu, L., Li, F., and Wang, X. (2010). Novel anti-inflammatory and neuroprotective agents for Parkinson's disease. CNS Neurol. Disord. Drug
Targets 9, 232-240. doi: 10.2174/ 187152710791012035

Ma, D. K., Bonaguidi, M. A., Ming, G.-L., and Song, H. (2009). Adult neural stem cells in the mammalian central nervous system. Cell Res. 19, 672-682. doi: 10.1038/cr.2009.56

Mandyam, C. D., Harburg, G. C., and Eisch, A. J. (2007). Determination of key aspects of precursor cell proliferation, cell cycle length and kinetics in the adult mouse subgranular zone. Neuroscience 146, 108-122. doi 10.1016/j.neuroscience.2006.12.064

Massa, F., Koehl, M., Wiesner, T., Grosjean, N., Revest, J. M., Piazza, P. V., et al. (2011). Conditional reduction of adult neurogenesis impairs bidirectional hippocampal synaptic plasticity. Proc. Natl. Acad. Sci. U.S.A. 108, 6644-6649. doi: 10.1073/pnas. 1016928108

McIver, S. R., Muccigrosso, M. M. and Haydon, P. G. (2012). The effect of doxycycline on alcohol consumption and sensitivity: consideration for inducible transgenic mouse models. Exp. Biol. Med. (Maywood) 237, 1129-1133. doi: 10.1258/ebm.2012.012029

Mignone, J. L., Kukekov, V., Chiang, A. S., Steindler, D., and Enikolopov, G. (2004). Neural stem and progenitor cells in nestin-GFP transgenic mice. J. Comp. Neurol. 469, 311-324. doi: 10.1002/cne.10964

Monje, M. L., Mizumatsu, S., Fike, J. R., and Palmer, T. D. (2002). Irradiation induces neural precursor-cell dysfunction. Nat. Med. 8, 955-962. doi 10.1038/nm749

Murthy, V. N., Schikorski, T., Stevens, C. F., and Zhu, Y. (2001). Inactivity produces increases in neurotransmitter release and synapse size. Neuron 32, 673-682. doi: 10.1016/S0896-6273(01)00500-1

Ng, S. Y., Semple, B. D., MorgantiKossmann, M. C., and Bye, N (2012). Attenuation of microglial activation with minocycline is not associated with changes in neurogenesis after focal traumatic brain injury in adult mice. J. Neurotrauma 29, 1410-1425. doi: 10.1089/neu.2011.2188

Nolte, C., Matyash, M., Pivneva, T., Schipke, C. G., Ohlemeyer C., Hanisch, U. K., et al. (2001). GFAP promoter-controlled EGFPexpressing transgenic mice: a tool to visualize astrocytes and astrogliosis in living brain tissue. Glia 33, 72-86.

Palmer, T. D., Takahashi, J., and Gage, F. H. (1997). The adult rat hippocampus contains primordial neural stem cells. Mol. Cell. Neurosci. 8, 389-404. doi: 10.1006/mcne.1996.0595
Peixoto, R. T., Kunz, P. A., Kwon, H., Mabb, A. M., Sabatini, B. L., Philpot, B. D., et al. (2012). Transsynaptic signaling by activity-dependent cleavage of neuroligin-1. Neuron 76, 396-409. doi: 10.1016/j.neuron.2012.07.006

Richter, C., Thieme, S., Bandola, J., Laugsch, M., Anastassiadis, K., and Brenner, S. (2013). Generation of inducible immortalized dendritic cells with proper immune function in vitro and in vivo. PLoS ONE 8:e62621. doi: 10.1371/journal.pone.0062621

Romero-Grimaldi, C., MurilloCarretero, M., Lopez-Toledano, M. A., Carrasco, M., Castro, C., and Estrada, C. (2011). ADAM-17/tumor necrosis factoralpha-converting enzyme inhibits neurogenesis and promotes gliogenesis from neural stem cells. Stem Cells 29, 1628-1639. doi: $10.1002 /$ stem. 710

Samuels, B. A., and Hen, R. (2011). Neurogenesis and affective disorders. Eur. J. Neurosci. 33, 1152-1159. doi: $\quad 10.1111 /$ j.1460-9568.2011. 07614.x

Santarelli, L., Saxe, M., Gross, C., Surget, A., Battaglia, F., Dulawa, S., et al. (2003). Requirement of hippocampal neurogenesis for the behavioral effects of antidepressants. Science 301, 805-809. doi: 10.1126/science.1083328

Saxe, M. D., Battaglia, F., Wang, J. W., Malleret, G., David, D. J., Monckton, J. E., et al. (2006). Ablation of hippocampal neurogenesis impairs contextual fear conditioning and synaptic plasticity in the dentate gyrus. Proc. Natl. Acad. Sci. U.S.A. 103, 17501-17506. doi: 10.1073/pnas.0607207103

Saxe, M. D., Malleret, G., Vronskaya, S., Mendez, I., Garcia, A. D. Sofroniew, M. V., et al. (2007). Paradoxical influence of hippocampal neurogenesis on working memory. Proc. Natl. Acad. Sci. U.S.A. $\quad 104, \quad 4642-4646 . \quad$ doi: 10.1073/pnas.0611718104

Shors, T. J., Anderson, M. L., Curlik, D. M., 2nd, and Nokia, M. S. (2012). Use it or lose it: how neurogenesis keeps the brain fit for learning. Behav. Brain Res. 227, 450-458. doi: 10.1016/j.bbr.2011. 04.023

Stegmeier, F., Hu, G., Rickles, R. J., Hannon, G. J., and Elledge, S. J. (2005). A lentiviral microRNAbased system for single-copy polymerase II-regulated RNA interference in mammalian cells. Proc. Nat Acad. Sci. U.S.A. 102, 13212-13217. doi: $10.1073 /$ pnas. 0506306102 
Svedin, P., Hagberg, H., Savman, K., Zhu, C., and Mallard, C. (2007). Matrix metalloproteinase- 9 gene knock-out protects the immature brain after cerebral hypoxia-ischemia. J. Neurosci. 27, 1511-1518. doi: 10.1523/ JNEUROSCI.4391-06.2007

Taupin, P. (2007). BrdU immunohistochemistry for studying adult neurogenesis: paradigms, pitfalls, limitations, and validation. Brain Res. Rev. 53, 198-214. doi: 10.1016/j. brainresrev.2006.08.002

Thomas, M., Le, W. D., and Jankovic, J. (2003). Minocycline and other tetracycline derivatives: a neuroprotective strategy in Parkinson's disease and Huntington's disease. Clin. Neuropharmacol. 26, 18-23. doi: 10.1097/00002826-20030100000005

Thuret, S., Toni, N., Aigner, S., Yeo, G. W., and Gage, F. H. (2009). Hippocampus-dependent learning is associated with adult neurogenesis in MRL/MpJ mice. Hippocampus 19, 658-669. doi: 10.1002/hipo. 20550

Toni, N., Laplagne, D. A., Zhao, C., Lombardi, G., Ribak, C. E., Gage, F. H., et al. (2008). Neurons born in the adult dentate gyrus form functional synapses with target cells. Nat. Neurosci. 11, 901-907. doi: 10.1038/nn.2156

Toni, N., and Sultan, S. (2011). Synapse formation on adult-born hippocampal neurons. Eur. J. Neurosci. 33, 1062-1068. doi: 10.1111/j.1460-9568.2011.07604.x

Toni, N., Teng, E. M., Bushong, E. A., Aimone, J. B., Zhao, C., Consiglio, A., et al. (2007). Synapse formation on neurons born in the adult hippocampus. Nat. Neurosci. 10, 727-734. doi: 10.1038/nn1908

Tronel, S., Belnoue, L., Grosjean, N., Revest, J. M., Piazza, P. V., Koehl, M., et al. (2012). Adultborn neurons are necessary for extended contextual discrimination. Hippocampus 22, 292-298. doi: 10.1002/hipo.20895

Trouche, S., Bontempi, B., Roullet, P., and Rampon, C. (2009). Recruitment of adult-generated neurons into functional hippocampal networks contributes to updating and strengthening of spatial memory. Proc. Natl. Acad. Sci. U.S.A. 106, 5919-5924. doi: 10.1073/pnas. 0811054106

Van Praag, H., Kempermann, G., and Gage, F. H. (1999). Running increases cell proliferation and neurogenesis in the adult mouse dentate gyrus. Nat. Neurosci. 2, 266-270. doi: 10.1038/6368

Van Praag, H., Schinder, A. F., Christie, B. R., Toni, N., Palmer, T. D., and Gage, F. H. (2002). Functional neurogenesis in the adult hippocampus. Nature 415, 1030-1034. doi: 10.1038/4151030a

Vukovic, J., Colditz, M. J., Blackmore, D. G., Ruitenberg, M. J., and Bartlett, P. F. (2012). Microglia modulate hippocampal neural precursor activity in response to exercise and aging. J. Neurosci. 32, 6435-6443. doi: 10.1523/JNEUROSCI.5925-11.2012

Wang, X. B., Bozdagi, O., Nikitczuk, J. S., Zhai, Z. W., Zhou, Q., and Huntley, G. W. (2008). Extracellular proteolysis by matrix metalloproteinase-9 drives dendritic spine enlargement and long-term potentiation coordinately. Proc. Natl. Acad. Sci. U.S.A. 105, 19520-19525. doi: 10.1073/pnas.0807248105

Wideroe, M., Havnes, M. B., Morken, T. S., Skranes, J., Goa, P. E., and Brubakk, A. M. (2012). Doxycycline treatment in a neonatal rat model of hypoxia-ischemia reduces cerebral tissue and white matter injury: a longitudinal magnetic resonance imaging study. Eur. J. Neurosci. 36, 2006-2016. doi: 10.1111/j.14609568.2012.08114.x

Yamaguchi, M., Saito, H., Suzuki, M., and Mori, K. (2000). Visualization of neurogenesis in the central nervous system using nestin promoter-GFP transgenic mice. Neuroreport 11, 1991-1996. doi: 10.1097/00001756-20000626000037

Yang, C. P., Gilley, J. A., Zhang, G. and Kernie, S. G. (2011). ApoE is required for maintenance of the dentate gyrus neural progenitor pool. Development 138, 4351-4362. doi: 10.1242/dev.065540

Yao, J., Mu, Y., and Gage, F. H. (2012) Neural stem cells: mechanisms and modeling. Protein Cell 3, 251-261. doi: 10.1007/s13238-012-2033-6

Yoon, S. Y., Patel, D., and Dougherty, P. M. (2012). Minocycline blocks lipopolysaccharide induced hyperalgesia by suppression of microglia but not astrocytes. Neuroscience 221, 214-224. doi: 10.1016/j. neuroscience.2012.06.024

Yrjanheikki, J., Keinanen, R., Pellikka, M., Hokfelt, T., and Koistinaho, J. (1998). Tetracyclines inhibit microglial activation and are neuroprotective in global brain ischemia. Proc. Natl. Acad.
Sci. U.S.A. 95, 15769-15774 doi: 10.1073/pnas.95.26.15769

Zhao, C., Teng, E. M., Summers, R. G. Jr., Ming, G. L., and Gage, F. H. (2006). Distinct morphological stages of dentate granule neuron maturation in the adult mouse hippocampus. J. Neurosci. 26, 3-11. doi: 10.1523/JNEUROSCI.3648-05.2006

Zhou, X., Vink, M., Klaver, B., Berkhout, B., and Das, A. T. (2006). Optimization of the TetOn system for regulated gene expression through viral evolution. Gene Ther. 13, 1382-1390. doi: 10.1038/sj.gt.3302780

Conflict of Interest Statement: The authors declare that the research was conducted in the absence of any commercial or financial relationships that could be construed as a potential conflict of interest.

Received: 24 May 2013; paper pending published: 13 June 2013; accepted: 08 July 2013; published online: 25 July 2013. Citation: Sultan S, Gebara E and Toni $N$ (2013) Doxycycline increases neurogenesis and reduces microglia in the adult hippocampus. Front. Neurosci. 7:131. doi: 10.3389/fnins.2013.00131

This article was submitted to Frontiers in Neurogenesis, a specialty of Frontiers in Neuroscience.

Copyright (c) 2013 Sultan, Gebara and Toni. This is an open-access article distributed under the terms of the Creative Commons Attribution License, which permits use, distribution and reproduction in other forums, provided the original authors and source are credited and subject to any copyright notices concerning any third-party graphics etc. 